\title{
Correction to: An improved cable-cylinder bracing system with quarter-ring yielding devices for seismic retrofit of steel moment frames
}

\author{
Oreste S. Bursi ${ }^{1} \cdot$ Nader Fanaie $^{2}$ D $\cdot$ Shervin Safaei Faegh ${ }^{2}$ (D) \\ Omid Sepasgozar Sarkhosh ${ }^{3}$ (D)
}

Published online: 31 May 2021

(c) Springer Nature B.V. 2021

\section{Correction to: Bulletin of Earthquake Engineering https://doi.org/10.1007/s10518-021-01108-x}

This erratum is published as typesetter overlooked several corrections and proofing errors introduced especially with figures.

Original article has been updated.

Publisher's Note Springer Nature remains neutral with regard to jurisdictional claims in published maps and institutional affiliations.

The original article can be found online at https://doi.org/10.1007/s10518-021-01108-X.

Nader Fanaie

fanaie@kntu.ac.ir

Oreste S. Bursi

oreste.bursi@unitn.it

Shervin Safaei Faegh

safaei.faegh.s@gmail.com

Omid Sepasgozar Sarkhosh

omid.sepasgozar@gmail.com

1 Department of Civil, Environmental and Mechanical Engineering, University of Trento, Trento, Italy

2 Faculty of Civil Engineering, Department of Civil Engineering, K. N. Toosi University of Technology, No. 1346, Valiasr St, PO Box, 15875-4416 Tehran, Iran

3 Faculty of Engineering, Department of Civil Engineering, University of Guilan, Rasht, Iran 